\title{
Life expectancy and income: \\ The Ben-Porath mechanism revisited
}

\author{
by \\ Casper Worm Hansen \\ and \\ Lars Lønstrup
}

Discussion Papers on Business and Economics

No. 3/2011
FURTHER INFORMATION
Department of Business and Economics
Faculty of Social Sciences
University of Southern Denmark
Campusvej 55
DK-5230 Odense M
Denmark

Tel.: +4565503271

Fax: +4565503237

E-mail:1ho@sam.sdu.dk 


\title{
Life expectancy and income: The Ben-Porath mechanism revisited
}

\author{
Casper Worm Hansen and Lars Lønstrup \\ University of Southern Denmark \& Netspar ${ }^{*}$
}

February 16, 2011

\begin{abstract}
In this paper we show that it may be optimal for individuals to educate themselves more and decrease future labor supply (choose earlier retirement) when life expectancy increases. This result reconciles the findings of Hazan [Hazan, M., 2009. Longevity and Lifetime Labor Supply: Evidence and Implications. Econometrica 77, 1829-1863] with theory. Further, the paper contributes to a better understanding of the conflicting empirical findings on the causal effect on income per capita from increased life expectancy.
\end{abstract}

Keywords: Life-cycle model; life expectancy; schooling; retirement

JEL Classification: D91; J22; J24; J26; O11

${ }^{*}$ University of Southern Denmark, Campusvej 55, 5230 Odense. Email: cwh@sam.sdu.dk

${ }^{\dagger}$ We thank Oded Galor, David Weil, Per Svejstrup and Peter Sandholt for useful suggestions. We also thank seminar participants at Brown University and University of Southern Denmark for comments 


\section{Introduction}

The theoretical literature on individuals' education decisions, initiated by the seminal work of Ben-Porath (1967), shares the conclusion that increasing life expectancy induces more schooling. The intuitive reasoning goes as follows: a longer (expected) working life, where the benefits from education are reaped, induces individuals to invest more in their human capital.

The consensus in the theoretical literature on schooling and life expectancy is, however, not reflected in the empirical counterpart. Accordingly, whether life expectancy has a positive effect on schooling, and thereby on income per capita, is highly debated. ${ }^{1}$ For example, Hazan (2009) refuses the hypothesis of increasing life expectancy as a causal factor of the observed rise in schooling over the last centuries (see Table 1).This conclusion rests upon what he denotes the Ben-Porath mechanism, which says that optimal schooling time increases if and only if lifetime working hours increase.

\begin{tabular}{|l|c|c|}
\hline & Average years of education & Expected working hours over lifetime \\
\hline Men born in 1850 & 8.71 & 114,728 \\
Men born in 1960 & 15.50 & 79,126 \\
\hline
\end{tabular}

Table 1: Source: Hazan (2009).

We argue that the description of incentives behind the so-called Ben-Porath mechanism, which is that individuals choose schooling time only with the purpose of maximizing the present value of lifetime earnings, delivers a knife-edge result relying crucially on an assumption of access to perfect financial markets. By relaxing this assumption we show that individuals' optimal response to increased life expectancy may be to increase schooling time and, at the same time, decrease future working hours where the schooling investments pay off in terms a higher hourly wage.

The purpose of the present paper is therefore to reconcile the empirical findings in Hazan (2009) with theory and thereby, more generally, to help explain the gap between the existing theory and the various empirical findings. We do this by using a simple three period lifecycle model in which we examine the partial equilibrium effects of an increased probability of survival to older ages on an individual's schooling, saving and retirement decisions. ${ }^{2}$ The model is based on two assumptions

\footnotetext{
${ }^{1}$ See the discussion below, where the recent results in the field are discussed and related to our finding. We further suggest how our model may be augmented to encompass general equilibrium effects that so far have not been explored.

${ }^{2}$ This means that the general equilibrium effects, including the effects of a changed population structure, are not a part of the argument. We discuss such complementary explanations below.
} 
about financial markets capturing realistic features of the incentive structure for the individual.

The first assumption carries the notion that more schooling comes of the cost at less consumption during youth. Thus, in our model, a young individual is unable to smooth consumption, via the financial market, between his schooling period and the rest of his life. By excluding borrowing in the financial markets as a way to finance consumption during the schooling period, the paper relates to the credit market imperfections (CMI) approach. For example, Kodde and Ritzen (1985) show the partial equilibrium effects of CMIs on schooling. More recently, the approach is used in a general equilibrium setting to study the implications of income distribution on economic growth, see e.g. Galor and Moav (2004). In the present paper, the exclusion of borrowing during schooling highlights an important part of the incentive structure during youth: spending more time in school means less time can be spent working. Thus, a lower standard of living during youth is an inevitable outcome of more schooling. This is true because higher future earnings induced by schooling cannot be smoothed between youth and future periods of life via financial services. ${ }^{3}$

The second assumption accounts for the effect of the mortality risk on the individual's saving decision. We do this by assuming that the interest on savings does not compensate for mortality risk, i.e. we assume absence of annuity markets. Therefore, if the uncertainty about the age at death decreases, which leads to an increase in life expectancy since the maximum attainable age is fixed, then the probability of dying before having exhausted nonannuitized wealth decreases. Consequently, an increase in life expectancy increases individuals' propensity to save, which makes their consumption profile steeper. As shown in Kalemli-Ozcan and Weil (2010), this effect tends to make individuals choose earlier retirement since increasing life expectancy increases the share of consumption at older ages financed by retirement savings. In our model, another way individuals can make their consumption profile steeper is to spend more time in school during youth. Due to credit market imperfections, individuals must work and consume less in their youth to increase schooling time and thereby future earnings (consumption). We provide and explain the condition to be fulfilled for this to be optimal when individuals, at the same time, choose to retire earlier, thereby lower their future working hours where the benefits from education are reaped.

The paper proceeds as follows. Section 2 describes a simple life cycle model and provides the result and the underlying intuition. Section 3 discusses the perspectives of the result regarding the divided empirical literature and mentions complementary explanations, based on general equilibrium effects, for why life expectancy has an ambiguous effect on income per capita. Section 4

\footnotetext{
${ }^{3}$ The assumptions of no borrowing during youth does not exclude the possibility of positive savings to smooth consumption across periods. However, in the schooling period, we regard this as a theoretical curiosity, and assume that the wage profile of individuals is such that it will never be optimal to hold postive wealth at the end of the schooling period (see below).
} 
offers some concluding remarks. Proofs are provided in the Appendix.

\section{The model}

Consider an individual who lives at most for three periods. In the first period, the individual is endowed with one unit of time and one unit of human capital. The unit time endowment is divided between schooling time, $e$, and labor supply $1-e$. Time spent in the labor market results in a real wage of $w_{1}>0$, which is therefore the opportunity cost of more schooling time. The first period wage income $w_{1}[1-e]$ is used solely for first period consumption, $c_{1}$ :

$$
c_{1}=w_{1}[1-e] .
$$

The first period budget constraint, in eq. (1), shows that individuals hold zero wealth at the end of the first period, a key part leading to our result. This may at first seem to be a restrictive assumption, but it may be the likely outcome of optimizing behavior if individuals could choose to (dis)save under the following two conditions. First, it requires that credit markets are sufficiently imperfect such that individuals choose to hold nonnegative wealth throughout life. ${ }^{4}$ Second, the lifetime wage profile must be sufficiently increasing such that individuals will not hold positive wealth (save) in the first period of life. In particular, let $w_{2}$ and $w_{3}$ denote the wage rate in the second and third period, respectively. Then, for a given utility function, there exists an $\epsilon \equiv \frac{w_{1}}{w_{1}+w_{2}+w_{3}}$ such that savings are non-positive in the first period of life. An alternative approach, which delivers qualitatively similar results, assumes that individuals live with their parents in the first period. In such a setting, the opportunity cost of education becomes forgone leisure (see among others Glomm and Ravikumar, 1992; Zhang and Zhang, 2005).

Survival to the second period is assumed to be certain. ${ }^{5}$ In the second period, each individual supplies one unit of efficient labor inelastically, and spends the wage income for consumption, $c_{2}$, and savings, $s>0$ :

$$
c_{2}=w_{2} h-s,
$$

where $w_{2}$ is the wage rate per unit of human capital. An individual's schooling time, $e$, increases the level of human capital according to the functional relation $h=h(e)$ where we assume $h_{e}(e)>0$ and $h(0)=1$.

\footnotetext{
${ }^{4}$ In fact, the assumption of no annuity markets implies that individuals cannot die in debt. This is true since a lender will always prefer a safe return in the capital market instead of lending money to a mortal individual unless he is compensated for the mortality risk, i.e. if annuity markets exist. However, more generally, there seems to be evidence of credit constraints hampering education (see Flug et al., 1998).

${ }^{5}$ Changing this assumption has no effect on our results below.
} 
Survival becomes uncertain at the end of the second period where $\phi \in(0,1)$ denotes the probability of surviving into the third period. Contingent on survival, the unit time endowment in the third period is divided between leisure, $l$, and working time, $1-l$. To facilitate the interpretation we denote $1-l$ as the retirement age. Labor market income in the third period, $w_{3} h[1-l]$, together with savings with accrued interest, $R s$, are used for third period consumption, $c_{3}:{ }^{6}$

$$
c_{3}=w_{3} h[1-l]+R s .
$$

Since annuity markets are absent, the return to savings is unaffected by the survival probability, $\phi$, i.e. individuals are not compensated with a higher interest rate when facing a lower probability of surviving (and vice versa). This implies that the saving behavior is affected on the margin by mortality risk. Furthermore, the absence of annuity markets implies that accidental bequests are generated by individuals dying at the end of the second period of life. For simplicity, we ignore these accidental bequests simply by assuming that they are thrown away. ${ }^{7}$

The preferences of an individual are represented by:

$$
\psi u\left(c_{1}\right)+u\left(c_{2}\right)+\phi\left[u\left(c_{3}\right)+\theta u(l)\right]
$$

where $\psi>0(\theta>0)$ is the taste for consumption (leisure) in the first (third) period. The standard assumptions are made about the utility function: $u_{x}>0$ and $u_{x x}<0, x=c_{1,2,3}, l$. We interpret eq. (4) as if each period of life has unit length, which means that life expectancy is given by $X \equiv 2+\phi$. Therefore, a rise in life expectancy is by definition caused by a lower uncertainty about the age at death. As shown below, this feature of the model, together with absence of annuity markets, is crucial for why individuals choose earlier retirement as life expectancy increases.

The problem for each individual consists of maximizing (4) subject to (1)-(3) by choosing $e, s$, and $l$. The necessary conditions for a maximum are:

$$
\begin{gathered}
-\psi w_{1} u_{c_{1}}+u_{c_{2}} w_{2} h_{e}+\phi u_{c_{3}} w_{3} h_{e}[1-l]=0 \\
-u_{c_{2}}+\phi R u_{c_{3}}=0 \\
-u_{c 3} w_{3} h+\theta u_{l}=0
\end{gathered}
$$

\footnotetext{
${ }^{6}$ Eq. (3) shows that we, for simplicity, assume no depreciation of human capital from the second to the third
} period of life. Introducing depreciation into the model does not change the results.

${ }^{7}$ Incorporating accidental bequests into the model does not necessarily change our results. Indeed, assuming that accidental bequests are distributed to the individuals in their first period of life actually strengthens the result for education time, although it weakens the result obtained for the retirement age. 
where we have assumed an interior solution for savings, $s$, and retirement age, $1-l$. Eq determines the optimal level of education (and $c_{1}$ ). Eq. (6) balances the marginal cost and benefit of saving in terms of marginal utilities. Finally, the retirement age is determined by eq. (7).

Combining the two first-order conditions in eqs. (5) and (6) yields:

$$
w_{2} h_{e}+\frac{w_{3}}{R} h_{e}[1-l]=w_{1} \psi \frac{u_{c_{1}}}{u_{c_{2}}}
$$

Eq. (8) shows that allocation of consumption matters for the schooling choice of credit constrained individuals, i.e. Fisher's seperation theorem does not apply (see for example, Kodde and Ritzen, 1985). The sum of the two terms on the left-hand side is the marginal utility benefit of education. These terms reveal that lifetime uncertainty affects the education choice only from its effect on marginal utility of second period consumption, $u_{c_{2}}$, via eq. (6). Intuitively, a rise in the probability of surviving into the third period, $\phi$, induces individuals to increase the propensity to save, which tends to decrease second period consumption. In order to spread out the implied decline in consumption before the third period, individuals increase the time spent on schooling in the first period of life. Consequently, individuals may find it optimal to be better educated even though the future working labor supply, where the benefits from schooling are reaped, will be reduced as a result.

If individuals, on the contrary, would have been able to smooth consumption between the first and second period, then eq. (8) would change to: ${ }^{8}$

$$
w_{2} h_{e}+\frac{w_{3}}{R} h_{e}[1-l]=w_{1} R
$$

In that case, the seperation theorem applies since schooling is decided only with the objective of maximizing present value lifetime income. In this case the standard result emerges: an earlier exit from the labor market $(1-l$ decreases), for example due to a rise in $\phi$, goes hand in hand with less schooling time $\left(h_{e}\right.$ increases).

Based on this conventional theoretical result, Hazan (2009) concludes that increased life expectancy is not a causal factor behind the rise in education since he observes a fall in lifetime working hours over the studied period. However, as we show here, this conclusion relies on access to perfect financial markets enabling individuals to smooth consumption between the first and the second period of life. Thus, our counterintuitive result, which is that individuals choose more schooling and at the same time choose to work less after schooling, shows that the empirical finding in Hazan (2009) may, in addition to general equilibrium effects, be driven by first order effects due to changed life cycle behavior. Furthermore, our result has important implications for the net effect on human capital and thereby the size of the effective labor force caused by increasing life

\footnotetext{
${ }^{8}$ Because the following relation would apply: $\psi u_{c_{1}}=R u_{c_{2}}$.
} 
expectancy. ${ }^{9}$ In particular, the quality and quantity of an individual's lifetime labor supply may go in different directions. Therefore, it is not clear, even when abstracting from general equilibrium effects, in what way we should expect an exogenous increase in life expectancy to affect economic performance.

We now turn to comparative statics to show the result formally and get a better understanding of the forces behind it. To fix ideas and intuition, we start out by assuming that each individual takes the retirement age as exogenously given to show the effect on education from changes in life expectancy and the retirement age. Subsequently, we keep education constant to focus on how the retirement choice is affected by the increase in life expectancy. Finally, we combine the results and show the overall finding.

The effect on education from an increase in life expectancy is provided in the following proposition:

Proposition 1 Holding the retirement age fixed, an exogenous rise in the survival probability, $\phi$, unambiguously increases the time spent on education.

A rise in $\phi$ makes individuals attach more importance to the third period of life and they are therefore more inclined to save. This entails more time devoted to schooling in the first period because schooling is the only instrument by which individuals can smooth consumption between the first and second period, i.e. the only way that transferring more ressources to the third period of life can be smoothed between the first and the second period of life.

The next piece of the overall result is the relation between schooling and the retirement age. Consider an exogenous fall in the retirement age:

Proposition 2 An exogenous fall in the retirement age, 1-l, has a nonnegative effect on schooling time, $e$, if the following conditions holds:

$$
-\frac{1+R^{2} \phi \frac{u_{c_{3} c_{3}}}{u_{c_{2} c_{2}}}}{w_{2} R h+[1-l] w_{3} h} \leq 1 .
$$

Proposition 2 states that time devoted to schooling and the retirement age may be negatively related. Intuitively, a lower retirement age augments the need for savings from the second to the third period of life. This has two counteracting effects on schooling time. The decline in lifetime working hours due to earlier retirement tends to decrease schooling time, which is the standard Ben-Porath mechanism. However, in our model the potential decrease in the standard of living in the second period, due to higher savings, can only be counterbalanced by an increase in schooling,

\footnotetext{
${ }^{9}$ Actually, in our model, lifetime labor supply shrinks both because of earlier retirement and later entry into the labor market. We focus here on the former effect wereas the latter effect is analyzed in more detail in Sheshinski (2009).
} 
since the schooling decision also determines the allocation of consumption. If condition (9) is satisfied, the latter effect dominates the former and individuals find it optimal to spend more time in school even when the number of future working hours shrinks.

The final piece of the overall result is how the retirement age is affected by $\phi$. Holding education fixed gives rise to the following proposition:

Proposition 3 Holding education fixed, an exogenous rise in the survival probability, $\phi$, unambiguously lowers the age of retirement.

The result stated in Proposition 3 is quite intuitive in the sense that the absence of annuity markets makes individuals save as if they were to live to the (constant) maximum attainable age regardless of the probability of surviving into the third period. Consequently, a higher survival probability makes individuals increase their saving propensity, which permits a lower retirement age. This is the main result of Kalemli-Ozcan and Weil (2010), although there is no ambiguity in the result from our model since we keep the maximum attainable age constant. ${ }^{10}$

This result, together with Propositions 1 and 2, enables us to conclude that a rise in $\phi$ may reduce lifetime working hours and at the same time increase schooling time.

To illustrate our result, with all the variables of interest being endogenous (schooling, saving and retirement), we apply the functional form $u(x)=\ln x$, which leads to the following solutions for education time and leisure time, respectively:

$$
\begin{aligned}
& e=\frac{1+\phi}{1+\phi+\frac{\psi}{\mu}} \\
& l=\theta \frac{1+R \frac{w_{2}}{w_{3}}}{1+\theta+\frac{1}{\phi}},
\end{aligned}
$$

where $\mu \equiv \frac{h_{e}}{h} e>0$ is asummed to be consant. Equations (10) and (11) lead to the following proposition:

Proposition 4 When $u=\ln x$, an exogenous rise in the survival probability, $\phi$, has a positive effect on schooling time, $e$, and at the same time a negative effect on the retirement age, $1-l$.

Proposition 4 provides an example from which we obtain the abovementioned result when schooling, savings and retirement are all endogenously determined. Besides the advantage of an analytical solution, the logarithmic case is a convenient benchmark showing that our esult does

\footnotetext{
${ }^{10}$ Another reason why there is no ambiguity in Proposition 3 is that we neglect the income effect from unintended bequests, which is analyzed in Hansen and Lønstrup (2010). However, the overall conclusion made in the present paper does not depend on assumptions regarding unintended bequests.
} 
not rely on any favoring of income or substitution effects from increasing wage income. It is worth mentioning that the effect on education does not depend on how responsive earnings are to schooling, captured by $\mu$, except for the assumptions made on $h_{e}$ above. In the next section, we discuss the implications of our result for the empirical analyses on the causal effect of increasing life expectancy on income.

\section{Life expectancy and income}

As argued above, rising life expectancy may cause an ambiguous effect on an individual's lifetime supply of human capital, even when we abstract from general equilibrium and aggregation effects caused by a changed population structure. Below we argue that our result may contribute to a better theoretical understanding of the mixed findings in the empirical literature by analyzing whether cross country variation in life expectancy can explain variation in income per capita.

Most empirical papers testing the causal effect running from life expectancy to income, presumes that increasing life expectancy tend to increase human capital accumulation via the Ben-Porath mechanism (see for instance Acemoglu and Johnson, 2007; Lorentzen et al. 2008; Jayachandran and Lleras-Muney 2009; Aghion et al. 2010). Nevertheless, the result of Hazan (2009) suggests that there might be no such relation at all. In order to link this finding, to the general discussion of whether life expectancy can explain cross country variation in income per capita, we now examine the supply side of an economy. Suppose that economy $i$ has the following production function:

$$
\log y_{i}=\alpha \log h_{i}-[1-\alpha] \log N_{i}
$$

where $0<\alpha<1, y_{i} \equiv \frac{Y_{i}}{N_{i}}$ denotes the income per capita, $h_{i}=e_{i} n_{i}$ is supply of human capital per capita given by the product of the representative individual's education, $e_{i}$, and labor supply, $n_{i}$. The size of the total population is given by $N_{i}$. Suppose further, along the lines of Acemoglu and Johnson (2007), that the following relations holds:

$$
\begin{gathered}
e_{i}=X_{i}^{\varepsilon} \\
n_{i}=X_{i}^{\nu} \\
N_{i}=X_{i}^{\lambda},
\end{gathered}
$$

which inserted into eq. (12) yields: 


$$
y_{i}=[\alpha[\varepsilon+v]-[1-\alpha] \lambda] \log X_{i} .
$$

In terms of the specification in eq. (1), the Ben-Porath mechanism suggests that $\varepsilon>0$ if and only if $v>0$. In that case, the theoretical reasoning behind a negative sign will rely on decreasing returns to scale (the "malthusian effect" ), assuming $\lambda>0 .{ }^{11}$ On the other hand, our model shows that optimal behavior may entail a situation where $\varepsilon>0$ and at the same time $v<0$. Thus, our model demonstrates counteracting channels causing an ambiguous result on the net effect on the stock of human capital when life expectancy increases exogenously. Therefore, the net effect from life expectancy to income per capita may be negative not only because of decreasing returns to scale but also due to a decreasing effect on the quantity of labor supplied. More generally, our analysis indicates that the Ben-Porath mechanism may overstate the effect on human capital due to gains in life expectancy depending on financial market imperfections and at which ages the mortality rate declines.

Furthermore, our theory also suggests a positive link between life expectancy and savings and thereby (in a general equilibrium setting) the accumulation of physical capital. This is an argument for why increasing life expectancy, via its effects on capital accumulation, has been instrumental in the rise in education. The mechanism could operate through the adjustment of factor prices (see Ludwig and Vogel, 2010) or it may operate more directly by affecting individuals' incentive to invest in their human capital. Specifically, suppose that an individual's level of human capital is determined by the amount of schooling, and that the growth rate of total factor productivity, $g$, is determined by the function $h=h(e, g)$. Following the thinking of Galor and Weil (2000) one may assume that $h_{e g}>0$, which means that more technological progress, i.e. the number of new technologies an individual is exposed (and must adapt) to during working life, raises the marginal return of education. Suppose further, as in Romer (1986), that there exists knowledge spillover from capital accumulation, ${ }^{12}$ making the growth rate of total factor productivity a positive function of savings. It follows that the positive link is established: a rise in life expectancy, through an increase in the saving rate, stimulates capital accumulation. The knowledge spillover hereof feeds into the growth rate of total factor productivity and thereby raises the incentive of individuals to invest in their human capital.

However, as argued in Boucekinne et al. (2002) there may a counteracting aggregation effect. In their model, increasing life expectancy causes the effective workforce to shrink in the long run since it is comprised of relatively older vintages of workers who are relatively less educated and therefore

\footnotetext{
${ }^{11}$ This will also be the case for a constant returns to scale production function with a fixed factor of production (e.g. land).

${ }^{12}$ I.e. a positive association between capital and total factor productivity.
} 
have a lower productivity. However, their result relies on the standard Ben-Porath mechanism, implying that an increase in life expectancy increases both lifetime working hours (the retirement age) and schooling time. As we have shown, this is not neccecarily the case in the abscence of perfect financial markets. Therefore, our result implies another positive effect from increased life expectancy on income per capita: earlier retirement and more schooling caused by higher life expectancy may circumvent the adverse effect of the relatively low productivity of a higher share of the workforce (the old workers).

\section{Concluding remarks}

Life expectancy may have important indirect effects on education via its effect on savings. This paper has shown the partial equilibrium effect where a higher propensity to save, induced by an increase in life expectancy, lead to earlier retirement and more schooling. This result provides a theoretical foundation for the finding in Hazan (2009) and more generally shows opposing effects on schooling when life expectancy increases. The result is complementary to various general equilibrium effects in explaining the mixed empirical findings on how life expectancy affects income per capita.

\section{Acknowledgement}

We thank Oded Galor, Per Svejstrup Hansen, Peter Sandholt Jensen and David N. Weil for useful suggestions. We also thank seminar participants at Brown University and University of Southern Denmark for comments.

\section{Appendix}

\section{Proof of Proposition 1}

Under the assumption of an exogenous retirement age the first order conditions reduces to equation. (5) and (6). Now we derive the following second order derivatives:

$$
\begin{gathered}
U_{s s}=u_{c_{2} c_{2}}+\phi R^{2} u_{c_{3} c_{3}}<0 \\
U_{e s}=-w_{2} h_{e} u_{c_{2} c_{2}}+\phi w_{3} h_{e}[1-l] R u_{c_{3} c_{3}} \lessgtr 0 \\
U_{s \phi}=R u_{c_{3}}>0
\end{gathered}
$$




$$
\begin{gathered}
U_{e \phi}=u_{c_{3}} w_{3} h_{e}[1-l]>0 \\
U_{s l}=-w_{3} h \phi R u_{c_{3} c_{3}}>0 \\
U_{e l}=-\phi u_{c_{3}} w_{3} h_{e}-\phi w_{3}^{2} h_{e} h[1-l] u_{c_{3} c_{3}} \gtrless 0
\end{gathered}
$$

By taking the total differential of eqs. (5) and (6) and solving the subsequent system of equation for $\frac{\partial e}{\partial \phi}$ we obtain:

$$
\frac{\partial e}{\partial \phi}=\frac{\left|\begin{array}{cc}
U_{s s} & -U_{s \phi} \\
U_{e s} & -U_{e \phi}
\end{array}\right|}{|H|}
$$

where $H$ is the Hessian matrix. For the problem to have a unique solution we assume that $|H|>0$.

Thus, sign $\frac{\partial e}{\partial \phi}=\left|\begin{array}{cc}U_{s s} & -U_{s \phi} \\ U_{e s} & -U_{e \phi}\end{array}\right|$. Inserting the expressions in eqs. (17)-(20) yields:

$$
\operatorname{sign} \frac{\partial e}{\partial \phi}=\operatorname{sign}\left[-u_{c_{2} c_{2}} u_{c_{3}} h_{e}\left[[1-l] w_{3}+R w_{2}\right]\right]>0
$$

which proofs Proposition 1 since $u_{c_{2} c_{2}}<0$ by assumption.

\section{Proof of Proposition 2}

The proof is analogous to the proof of Proposition 1. Thus:

$$
\begin{gathered}
\frac{\partial e}{\partial l}=\frac{\left|\begin{array}{ll}
U_{s s} & -U_{s l} \\
U_{e s} & -U_{e l}
\end{array}\right|}{|H|} \\
\operatorname{sign} \frac{\partial e}{\partial \phi}=\operatorname{sign}\left[\phi w_{3} h_{e} u_{c_{3} c_{3}}\left[u_{d} R^{2} \phi+u_{c_{3}} \frac{u_{c_{2} c_{2}}}{u_{c_{3} c_{3}}}+h w_{2} u_{c_{2} c_{2}} R+[1-l] h u_{c_{2} c_{2}} w_{3}\right]\right] \lessgtr 0,
\end{gathered}
$$

which is ambigious. However, simple algebra shows that if the following condition holds

$$
-\frac{R^{2} \phi+\frac{u_{c_{2} c_{2}}}{u_{c_{3} c_{3}}}}{w_{2} R h+(1-l) w_{3} h} \frac{u_{c_{3} c_{3}}}{u_{c_{2} c_{2}}} \leq 1
$$

then a fall in the retirement age has a nonnegative effect on schooling time.

\section{Proof of Proposition 3}

Follows from straightforward differentiation of eqs. (10) and (11).

\section{Proof of Proposition 4}


The proof is analogue to that of Proposition 1. Thus:

$$
\frac{\partial l}{\partial \phi}=\frac{\left|\begin{array}{cc}
U_{s s} & -U_{s \phi} \\
U_{l s} & -U_{l \phi}
\end{array}\right|}{|H|}
$$

By inserting the expressions for the second order derivatives we obtain the following expression:

$$
\operatorname{sign} \frac{\partial l}{\partial \phi}=\operatorname{sign}\left[u_{c_{3}}\right]>0 .
$$

Hence, a rise in $\phi$ lowers the age of retirement $(1-l)$.

\section{References}

Acemoglu, D., and Johnson, S., 2007. Disease and Development: The Effect of Life Expectancy on Economic Growth. Journal of Political Economy 115 (6), 925-985.

Aghion, P., Howitt, P., Murtin, F., 2010. The relationship between health and growth: When Lucas Meets Nelson-Phelps. Working paper 15813. NBER.

Ben-Porath, Y., 1967. The Production of Human Capital and the Life Cycle of Earnings: Journal of Political Economy, 75, 352-365.

Boucekinne, R., de la Croix, D., and Licandro, O., 2002. Vintage Human Capital, Demographic Trends, and Endogenous Growth. Journal of Economic Theory 104, 340-375.

Flug K., Spilimbergo A., and Wachtenheim, E., 1998. Investment in Education: Do Economic Volatility and Credit Constraints Matter? Journal of Development Economics 55, 465-481.

Galor, O., and Moav, O., 2004. From Physical to Human Capital Accumulation: Inequality and the Process of Development. Review of Economic Studies 71, 1001-1026.

Galor, O., and Weil, D.N., 2000. Population, technology, and growth: from the Malthusian stagnation to the demographic transition and beyond. American Economic Review 90 (4), 806-828.

Glomm, G., and Ravikumar, B., 1992. Public versus Private Investment in Human Capital: Endogenous Growth and Income Inequality. Journal of Political Economy 100, 818-834.

Hansen, C., and Lønstrup, L., 2010. Aging, Imperfect Annuity Markets and Retirement. University of Southern Denmark, Working paper. (available from www.ssrn.com) 
Hazan, M., 2009. Longevity and Lifetime Labor Supply: Evidence and Implications. Econometrica 77, 1829-1863.

Jayachandran, S., and Lleras-Muney, A., 2009. Life Expectancy and Human Capital Investments: Evidence from Maternal Mortality Declines. Quaterly Journal of Economics 124 (1), 349-397.

Kalemli-Ozcan, S., and Weil, D.N., 2010. Mortality change, the uncertainty effect, and retirement. Journal of Economic Growth 15, 65-91.

Kodde, D.A., and Ritzen, J.M.M., 1985. The Demand for Education under Capital Market Imperfections. European Economic Review 28, 347-362.

Lorentzen, P., McMillan, J., and Wacziarg, R., 2008. Death and Development. Journal of Economic Growth, vol.13 (2), 81-124.

Ludwig, A., and, Vogel, E., 2010. Mortality, fertility, education and capital accumulation in a simple OLG economy. Journal of Population Economics 23, 703-735.

Romer, P.M., 1986. Increasing returns and long-run growth. Journal of Political Economy 94, 1002-1037.

Sheshinski, E., 2009. Uncertain Longevity and Investment in Education. The Hebrew University of Jerusalem, Working paper.

Zhang, J., and Zhang, J., 2005. The Effect of Life Expectancy on Fertility, Saving, Schooling and Economic Growth: Theory and Evidence. Scandinavian Journal of Economics 107 (1), 45-66. 